\title{
KERAGAAN AGROINDUSTRI SALE PISANG GULUNG (Studi Kasus pada Agroindustri Rizki Barokah di Desa Sukahurip Kecamatan Pamarican Kabupaten Ciamis)
}

\author{
AGROINDUSTRY PERFORMANCE OF ROLL BANANA SALE \\ (Case Study On Rizki Barokah Agroindustry at Sukahurip Village, Pamarican District, \\ Cimis Regerency)
}

\author{
RISKA MELLYANA APRILIA ${ }^{1}$, TRISNA INSAN NOOR $^{2}$, BUDI SETIA ${ }^{1}$ \\ ${ }^{1}$ Fakultas Pertanian Universitas Galuh \\ ${ }^{2}$ Fakultas Pertanian Universitas Padjajaran \\ *E-mail: riskamellyana26@gmail.com
}

\begin{abstract}
ABSTRAK
Penelitian ini bertujuan untuk mengetahui : 1) Proses produksi agroindustri sale pisang gulung Rizki Barokah di Desa Sukahurip Kecamatan Pamarican Kabupaten Ciamis, 2) Saluran pemasaran Agroindustri sale pisang gulung Rizki Barokah di Desa Sukahuri Kecamatan Pamarican Kabupaten Ciamis, 3) Pendapatan Agroindustri sale pisang gulung Rizki Barokah di Desa Sukahurip Kecamatan Pamarican Kabupaten Ciamis. Jenis penelitian yang digunakan adalah kuantitatif dengan pendekatan deskriptif studi kasus pada Agroindustri sale pisang gulung Rizki Barokah di Desa Sukahurip Kecamatan Pamarican Kabupaten Ciamis. Teknik penarikan sampel dalam penelitian ini dilakukan secara purposive sampling yaitu pada Agroindustri sale pisang gulung Rizki Barokah hasil penelitian menunjukkan bahwa, 1) Proses produksi sale pisang gulung Rizki Barokah terlebih dahulu mempersiapkan bahan baku yaitu babangi pisang dan tepung terigu sebagai pelengkap tambahan untuk membuat sale pisang, selanjutnya proses pemotongan, penggulungan, pembuatan adonan, penggorengan dan pengemasan. 2) Saluran pemasaran sale pisang gulung Rizki Barokah menggunakan saluran tingkat 1 yaitu produsen - pengecer - konsumen, harga jual pengecer berkisar Rp. 28.000,00 perkilogram. 3) Pendapatan Agroindustri sale pisang gulung Rizki Barokah Rp. 201.154,13 dalam satu kali proses produksi.
\end{abstract}

Kata Kunci : Agroindustri, Keragaan, Pendapatan, Saluran Pemasaran, dan Proses Produksi

\section{ABSTRACT}

This study aims to determine: 1) The production process of Agroindustry roll banana sale of Rizki Barokah in Sukahurip Village, Pamarican District, Ciamis Regerency. 2) Agroindustry marketing channels for banana roll sale of Rizki Barokah in Sukahurip Village, Pamarican District, Ciamis Regerency. 3) Agroindustry income of Rizki Barokah banana roll sale in Sukahurip Village, Pamarican District, Ciamis Regency. The type of research used is quantitative with a descriptive case study approach to the Agroindustry of selling banana roll sale with Rizki Barokah in Sukahurip Village, Pamarican District, Ciamis Regency. The sampling technique in this study was carried out by purposive sampling, namely the Rizki Barokah banana roll sale Agroindustry. The results showed that, 1) The production process of Rizki Barokah banana roll sale prepared the raw materials, namely babangi banana and wheat flour as an additional complement to making banana sale, then the process of cutting, rolling, making dough, frying and packaging. 2) Rizki Barokah banana roll sale marketing channel uses level 1 channels, namely producers-retailers-consumers, retailers selling ranges from Rp.28.000,00 per kilograms. 3) Agroindustry income from Rizki Barokah banana rolls sale Rp. 201.154,13in one production process.

Keyword: Agroindustry, Performance, Income, Marketing Channels, and Production Process 


\section{PENDAHULUAN}

Agroindustri merupakan bagian (sub sistem) dari agribisnis yaitu industri yang memproses dan mentransformasikan hasil pertanian menjadi barang setengah jadi atau barang jadi yang langsung dapat dikonsumsi (Udayana,2011 dalam Pratiwi et al, 2017). Priyarsono dan Backe (2007) industri pengolahan berbasis pertanian (agroindustri) merupakan sektor yang akan mendorong pertumbuhan ekonomi nasional yang tinggi terutama agroindustri kecil dan menengah. Dalam rangka upaya peningkatan pendapatan petani mengembangkan agroindustri merupakan alternatif yang dapat dilakukan.

Pembangunan pertanian dalam hal ini sub sektor tanaman pangan khususnya komoditas hortikultura harus dapat tumbuh dengan cepat, agar secara fungsional akan semakin mampu berperan dalam penyediaan bahan baku industri, peningkatan pendapatan petani, penciptaan lapangan kerja serta peningkatan penerimaan devisa melalui ekspor hasilhasil tanaman hortikultura. Agroindustri merupakan suatu industripertanian yang kegiatannya terkait dengan sektor pertanian.

Bahan pangan sebagai salah satu kebutuhan primer bagi manusia, sangat intensif dijadikan kajian sebagai objek formal ilmu teknik dan ditopang oleh tuntunan industri, terutama di negara maju. Kegiatan penanganan, pengolahan, distribusi, dan pemasaran hasil pertanian dengan meningkatnya selera konsumen dalam hal cita rasa, fisik, standar gizi, maupun kesehatan (Mangunwidjaja dan Salih, 2002).

Buah pisang adalah salah satu komoditas pertanian yang dihasilkan para petani di wilayah Indonesia. Kabupaten Ciamis adalah salah satu Kabupaten penghasil buah buah pisang. Menurut informasi Dinas Pertanian Tanaman Pangan Kabupaten Ciamis, produksi pisang di Kabupaten Ciamis tersebar 26 Kecamatan dengan produksi tetinggi terdapat di Kecamatan Sekamantri dengan produksi 103.282,7 ton pada tahun 2019.

Kecamatan Pamarican merupakan daerah penghasil komoditas pisang ke 2 terendah di kabupaten Ciamis yang perpotensi untuk terus dikembangkan. Berdasarkan kesesuaian wilayah, maka potensi pengembangan agroindustri pada komoditas pisang untuk Kabupaten Ciamis khususnya Kecamatan Pamarican cukup besar untuk dikembangkan, karena tanaman pisang merupakan salah satu tanaman subsektor hortikultura yang diprioritaskan untuk pengembangan agroindustri di Kecamatan Pamarican. 
Yang pengembangannya perlu dikelola lebih lanjut sehingga pengembangan agroindustri khususnya komoditaas pisang bisa dijadikan peluang usaha untuk masyarakat Kecamatan Pamarican.

Pengembangan agroindustri pada komoditas pisang, pengolahan pisang yang menjadikan pisang sebagai produk olahan sale pisang merupakan salah satu cara untuk meningkatkan nilai ekonomi yang sangat baik dan mempunyai nilai jual yang tinggi. Seiring dengan perkembangan agroindustri, suatu industri dituntut untuk dapat mengembangkan produktivitas, efisiensi, dan daya saing untuk dapat berkompetisi dipasar lokal maupun nasional.

Usaha sale pisang "Rizki Barokah" mulai merintis usaha pengolahan sale pisang pada tahun 2010. Salah satu cara untuk memberikan nilai tambah terhadap komoditas buah pisang yaitu dengan cara pengolahan buah pisang menjadi sale pisang, selain akan menyerap tenaga kerja juga akan memberikan nilai tambah terhadap komoditas buah pisang dibandingkan dengan dijual langsung tanpa proses pengolahan.

\section{Identifikasi Masalah}

Berdasarkan uraian, pada latar belakang di atas maka masalah yang dapat di identifikasi dalam peneliti ini adalah :
1. Bagaimana proses produksi agroindustri sale pisang gulung Rizki Barokah di Desa Sukahurip Kecamatan Pamarican Kabupaten Ciamis?

2. Bagaimana saluran pemasaran agroindustri sale pisang gulung Rizki Barokah di Desa Sukahurip Kecamatan Pamarican Kabupaten Ciamis?

3. Berapa pendapatan agroindustri sale pisang gulung Rizki Barokah di Desa Sukahurip Kecamatan Pamarican Kabupaten Ciamis?

\section{Tujuan Penelitian}

Adapun tujuan dari penelitian ini adalah untuk :

1. Mengetahui proses produksi agroindustri sale pisang gulung Rizki Barokah di Desa Sukahurip Kecamatan Pamarican Kabupaten Ciamis.

2. Mengetahui saluran pemasaran agroindustri sale pisang sale pisang gulung Rizki Barokah di Desa Sukahurip Kecamatan Pamarican Kabupaten Ciamis.

3. Mengetahui pendapatan agroindustri sale pisang gulung Rizki Barokah di Desa Sukahurip Kecamatan Pamarican Kabupaten Ciamis. 


\section{METODE PENELITIAN \\ Jenis Penelitian}

Jenis penelitian ini adalah penelitian kuantitatif dengan pendekatan deskriptif yaitu studi kasus. Menurut Sugiono (2013: 13) metode penelitian kuantitatif dapat diartikan sebagai metode penelitian yang berdasarkan pada filsapat positivism, digunakan untuk meneliti pada populasi atau sampel tertentu, teknik pengumpulan sampel pada umumnya dilakukan secara random, pengumpulan data data menggunakan instumen penelitian, analisis dan bersifat kuantitat/statistic dengan tujuan untuk menguji hipotesis yang telah ditetapkan. Menurut Nazir (2011: 54) tujuan penelitian deskriptif adalah untuk membuat deskripsi, gambaran atau lukisan secara sistematis factual dan akurat mengenai fakta-fakta, sifat-sifat sera hubungan antara fenomena yang diselidiki.

\section{Teknik Pengumpulan Data}

Dalam penelitian ini menggunakan data primer dan sekun der

\section{Teknik Penarikan Sampel}

Metode yang digunakan dalam penarikan sampel ini adalah metode purposive sampling. Menurut Sugiono Natoatmodjo (2010) adalah teknik untuk menentukan sampel penelitian dengan beberapa pertimbangan tertentu yang bertujuan agar data yang diperoleh nantinya bisa lebih representatif. Dalam penelitian ini responden berjumlah satu orang yaitu bapak Ibrahim sebagai pemilik Agroindustri Sale Pisang gulung Rizki Barokah di Desa Sukahurip Kecamatan Pamarican Kabupaten Ciamis.

\section{Rancangan Analisis Data}

Analisis yang digunakan dalam penelitian ini adalah analisis deskriptif dan analisis usaha.

\section{Analisis Deskriptif}

Analisis deskriptif digunakan untuk menganalisis keragaan profil, keragaan saluran pemasaran dan pendapatan agroindustri sale pisang gulung Rizki Barokah di Desa Sukahurip Kecamatan Pamarican Kabupaten Ciamis. Menurut Sugiyono (2017:147), analisis desktiptif adalah statistik yang digunakan untuk menganalisis data dengan cara mendeskripsikan atau menggambarkan data yang telah terkumpul sebagaimana adanya tanpa bermaksud membuat kesimpulan yang berlaku untuk umum atau generalisasi.

2. Analisis Usaha

Analisis usaha yang digunakan terhadap data yang bersifat kuantitatif adalah analisis usaha dengan tujuan untuk mengetahui keuntungan yang diperoleh.

a. Biaya Total

Biaya Total adalah jumlah dari biaya variabel ditambah dengan biaya tetap 
dalam proses produksi. Menurut

Soekartawi (2002)

$\mathrm{TC}=\mathrm{TFC}+\mathrm{TVC}$

Dimana :

$\mathrm{TC}=$ Total Cost (Biaya Total)

TFC = Total Fixed Cost (Biaya Tetap

Total)

TVC = Total Variabel Cost (Biaya

Variabel Total)

b. Analisis Penerimaan

Untuk mengetahui besarnya penerimaan digunakan rumus sebagai berikut. (Rahim dan Hastuti, 2007).

$\mathrm{TR}=\mathrm{Y} \times \mathrm{Py}$

Dimana :

$\mathrm{TR}=$ Total Revenue (Penerimaan Total)

$\mathrm{Y}=$ Jumlah Produksi

Py = Harga

c. Analisis Pendapatan

Untuk mengetahui besarnya pendapatan digunakan rumus sebagai berikut. (Soekartawi, 2006:54).

$\mathrm{Pd}=\mathrm{TR}-\mathrm{TC}$

Dimana :

$\mathrm{Pd}=$ Pendapatan

$\mathrm{TR}=$ Total Revenue (Penerimaan

Total)

$\mathrm{TC}=$ Total Cost (Biaya Tetap)

d. Analisis R/C
R/C adalah ukuran perbandingan antara pendapatan dengan total biaya produksi. (Soekartawi, 2006).

$\mathrm{R} / \mathrm{C}=\mathrm{TR}-\mathrm{TC}$

Dimana :

$\mathrm{R} / \mathrm{C}=$ Revenue Cost Ratio

$T R=$ Total Revenue (Penerimaan Total)

$\mathrm{TC}=$ Total Cost (Biaya Total)

\section{Waktu dan Tempat Penelitian}

Penelitian ini akan dilaksanakan pada Agroindustri Sale Pisang gulung "Rizki Barokah" di Desa Sukahurip Kecamatan Pamarican Kabupaten Ciamis. Adapun waktu penelitian dibagi dalam tahapan sebagai berikut :

1. Tahap persiapan, yaitu survei pendahuluan, dan penulisan usulan penelitian direncanakan bulan Maret 2020.

2. Tahap pengumpulan data dari lapangan, yaitu pengumpulan data primer dan data data sekunder direncanakan pada bulan April 2020.

3. Tahap pengolahan dan analisis data, penyusunan serta 39 in skripsi direncanakan pad Mei 2020 sampai dengan selesai. 
HASIL DAN PEMBAHASAN

\section{Identitas Responden}

\section{Umur Perajin}

Diketahui bahwa umur perajin adalah

54 tahun. Dengan demikian responden berada pada usia produktif.

\section{Pendidikan}

Tingkat pendidikan

akan mempengaruhi taraf hidup dan kemajuan seseorang, karena secara langsung maupun tidak langsung akan mempengaruhi cara berfikirnya. Tingkat pendidikan yang tinggi diharapkan akan memudahkan dalam menerima dan menerapkan pengetahuan dan teknologi, sehingga akan menentukan keberhasilan suatu usaha.

$$
\text { Responden menamatkan }
$$

pendidikan formalnya sampai dengan Sekolah Menengah Pertama (SMP). Hal tersebut menunjukkan bahwa tingkat pendidikan responden telah memenuhi wajib belajar 9 tahun. Tingkat pendidikan perajin akan mempengaruhi terhadap keberhasilan usahanya, dengan demikian usaha yang dilakukan oleh perajin perlu didukung pelatihan mengenai agroindustri supaya usahanya semakin meningkat.

\section{Pengalaman Berusaha}

Berdasarkan hasil wawancara dengan responden diketahui bahwa pengalaman responden dalam menjalankan agroindustri Sale Pisang sudah berjalan selama 10 tahun. Sehingga dengan hal tersebut, perajin mempunyai pengalaman yang cukup lama, dengan demikian dapat dijadikan modal besar dalam berusaha.

\section{Tanggungan Keluarga}

Berdasarkan hasil wawancara banyaknya tanggungan keluarga adalah 4 orang, yang terdiri dari tiga anak dan satu istri.

\section{Profil Agroindustri Sale Pisang Gulung}

Agroindustri sale pisang gulung Rizki Barokah didirikan pada tahun 2010 oleh bapak Wahimin, agroindustri ini diberi nama Rizki Barokah oleh orang tuanya alasannya diberi nama Rizki Barokah biar usahanya semakin berkah. Pengalam dalam menjalankan agroindustri sale pisang gulung adalah berjalan selama 10 tahun sampai sekarang, sehingga pengrajin mempunyai pengalaman yang cukup lama, dengan demikian dapat dijadikan modal besar dalam berusaha. Agroindustri Rizki Barokah berdiri dengan menggunakan modal sendiri karena benar-benar dari nol untuk bisa merintis usaha tersebut.

Agroindustri Rizki Barokah didirikan dengan latar belakang kondisi wilayah masih rendahnya pendapatan desa dan banyak tenaga kerja yang menganggur terutama ibu-ibu rumah tangga. Tujuan khusus berdirinya agroindustri Rizki Barokah adalah untuk menyerap tenaga kerja, memejukan masyarakat desa, 
meningkatkan pendapatan desa, mencegah pengangguran, memajukan industri di desa, mengolah hasil pertanian. Adapun tujuan lain yang tidak lepas dari tujuan berdirinya suatu agroindustri adalah untuk memperoleh laba setinggi-tingginya untuk kepentingan pemilik dan kesejahteraan karyawan.

\section{Proses Produksi Sale Pisang Gulung}

Proses produksi yang dilakukan pada agroindustri sale pisang "Rizki Barokah" di Desa Sukahurip terlebih dahulu mempersiapkan bahan baku, pemotongan, penggulungan, pembuatan adonan, penggoregan, penirisan dan pengemasan. Secara rinci tahapan pengolahan sale pisang gulung sebagai berikut :

1. Pengadaan Bahan Baku

Kegiatan proses produksi bahan baku yang digunakan dalam pembuatan sale pisang ini pada umumnya yaitu babangi pisang dan bahan penunjang lainnya. Sumber pengadaan bahan baku babangi pisang umumnya berasal dari pengrajin yang ada di daerah sekitar pabrik. Sistem pembelian bahan baku yang dilakukan oleh agroindustri yaitu pembelian yang bertujuan menjaga ketersediaan bahan baku babangi pisang selama proses produksi. Pemebelian babangi pisang dengan harga sebesar Rp. 45.000 per $\mathrm{kg}$, tepung terigu Rp. 8.000 per $\mathrm{kg}$, tepung beras Rp. 12,000, minyak goreang Rp. 12.500, gula pasir Rp. 14.000 per $\mathrm{kg}$ dan garam Rp. 1.000 per pcs. Rata-rata babangi pisang yang diolah satu kali proses produksi sebanyak $30 \mathrm{~kg}, 15 \mathrm{~kg}$ tepung terigu. Minyak goring $30 \mathrm{~kg}$ dan garam 1 pcs.

2. Pemotongan

Pemotongan babangi pisang yang masih berbentuk lembaran memanjang kemudian dipotong menjadi kecilkecil atau sesuai ukuran dengan menggunakan alat pisau yang panjang.

3. Penggulungan

Babangi pisang yang sudah di potong kemudian dilem fungsinya untuk merekatkan bagian pucuk babangi pisang biar membentuk bulatan setelah itu digulung.

4. Pembuatan Adonan

Pembuatan adonan untuk melumuri babangi pisang yang telah digulung tersebut, campur tepung terigu, tepung beras, gula pasir dan garam campurak semua bahan tersebut sampai merata.

5. Penggorengan 
Sebelumnya panaskan minyak terlebih dahulu kemudian babangi pisang yang telah digulung dimasukan kedalam adonan, goreng sampai berubah warna kuning kecoklatan, lalu angkat dan tiriskan.

\section{Penirisan dan Pengemasan}

Hasil penggorengan selanjutnya di tririskan dengan menggunakan mesin spinner peniris minyak, kemudian dilakukan pengemasan, pemasangan label produk dan proses produksi sale pisang diakhiri dengan produk siap untuk dipasarkan keberbagai daerah.

\section{Hasil Produksi}

Hasil produksi sale pisang gulung pada Agroindustri Rizki Barokah di Desa Sukahurip Kecamatan Pamarican Kabupaten Ciamis yaitu dalam satu kali proses produksi membutuhkan 30 kilogram babangi pisang yang mentah untuk dapat menghasilkan 125 kilogram. Bahan baku utama yaitu babangi pisang 30 kilogram dan ada bahan tambahannya seperti margarin $10 \mathrm{bks}$, tepung beras $20 \mathrm{~kg}$, tepung terigu $15 \mathrm{~kg}$, gula pasir $5 \mathrm{~kg}$, garam $1 \mathrm{bks}$, minyak goring $30 \mathrm{~kg}$.

\section{Saluran Pemasaran}

Pemasaran sale pisang di Desa Sukahurip Kecamatan Pamarican Kabupaten Ciamis melalui dua saluran pemasaran yaitu pemasaran yang terlibat dalam saluran pemasaran dari produsen ke konsumen adalah pedagang pengecer.. Berdasarkan hasil penelitian diketahui bahwa perusahaan Rizki Barokah dalam penyaluran produk sale pisang gulung dapat dilihat pada Gambar 1.

Saluran I.

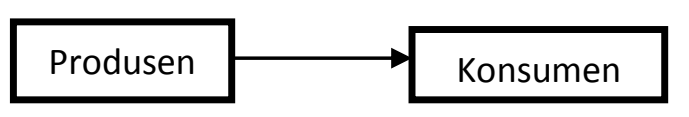

Saluran II.

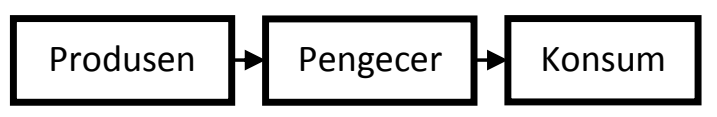

Sale pisang gulung dipasarkan dalam satuan rupiah perkilogram dengan harga Rp. 30.000,00 per kilogram. Untuk memperluas dan memperlancar pemasaran sale pisang sangat dibutuhkan peran lembaga pemasaran untuk menyalurkan sale pisang dari produsen hingga ke tangan konsumen. Deangan adanya saluran pemasaran yang digunakan menyebabkan tingkat marjin, biaya pemasaran dan keuntungan yang berbeda.

\section{Penerimaan}

Penerimaan yang diterima Agroindustri sale pisang gulung "Rizki Barokah" di Desa Sukahurip Kecamatan Pamarican Kabupaten Ciamis dilihat pada tabel 6 . 


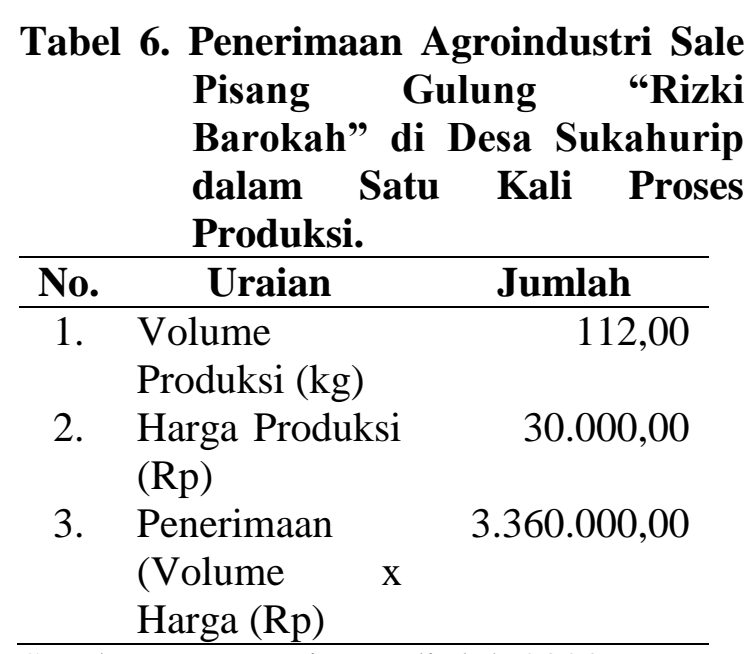

Sumber : Data Primer, diolah 2020

Berdasarkan Tabel 8 diketahui bahwa penerimaan Agroindustri sale pisang gulung “Rizki Barokah' di Desa Sukahurip yaitu Rp. 3.360.000,00 per satu kali produksi.

\section{Pendapatan}

Pendapatan adalah selisih antara penerimaan dengan biaya total (biaya tetap dan biaya variabel) pada agroindustri sale pisang gulung rizki barokah dapat dilihat pada Tabel 6.

Tabel 6. Penerimaan, biaya total, pendapatan Agroindustri Sale Pisang Gulung Rizki Barokah di Desa Sukahurip dalam satu kali proses produksi

\begin{tabular}{clr}
\hline No. & Komponen & \multicolumn{1}{c}{ Nilai $(\mathbf{R p )}$} \\
\hline 1. & Penerimaan & $3.360 .000,00$ \\
2. & Biaya Total & $3.158 .845,87$ \\
3. & Pendapatan & $201.154,13$ \\
\hline
\end{tabular}

Sumber : Data Primer, diolah 2020

Pendapatan merupakan hasil yang diperoleh dari selisih antara total penerimaan (TR) dikurangi dengan biaya total produksi (TC). Hasil penelitian menunjukkan bahwa pendapatan sale pisang gulung "Rizki Barokah" di Desa Sukahurip dalam satu kali proses produksi yaitu Rp 201.154,13. Dari pendapatan akan menghasilkan R/C sebesar 1,06 merupakan ratio atas penerimaan terhadap biaya dan dikatakan kelyakan finansial usaha sale pisang gulung "Rizki Barokah" dikatakan layak.

\section{Kemitraan}

Menurut Sutawi (dalamYuliani, 2004) kemitraan adalah kerjasama usaha antara usaha kecil dengan usaha menengah atau besar yang disertai dengan pembinaan dan pengembangan oleh usaha menengah atau usaha besar dengan memperhatikan prinsip saling menguntungkan.

Kemitraan usaha bertujuan untuk meningkatkan pendapatan, kesinambungan usaha, kuantitas produksi, kualitas produksi, meningkatkan kualitas kelompok mitra, peningkatan usaha dalam rangka menumbuhkan dan meningkatkan kemampuan usaha kelompok mitra mandiri (Martodireso dan Widada, 2001).

\section{KESIMPULAN DAN SARAN Kesimpulan}

Berdasarkan hasil dan pembahasan, maka dapat diambil kesimpulan sebagai berikut : 
1. Proses produksi Agroindustri Rizki Barokah masih mengunakan teknologi sederhana. Proses produksi sale pisang gulung secara garis besar dimulai dari pemotongan, penggulungan, penggorengan dan pengemasan.

2. Terdapat dua saluran pemasaran sale pisang gulung pada Agroindustri Rizki Barokah yaitu :

Saluran tingkat I: Produsen Konsumen.

Saluran Tingkat II: Produsen Penfecer - Konsumenn.

3. Besarnya pendapatan pada Agroindustri Rizki Barokah dalam satu kali proses produksi yaitu $\mathrm{Rp}$. $201.154,13$.

\section{Saran}

Berdasarkan kesimpulan tersebut, maka dapat disarankan hal-hal sebagai berikut :

1. Pengusaha Agroindustri Rizki Barokah sebaiknya menambah produksinya dengan menambahkan bahan baku dan lainnya, supaya lebih berkembang lagi menjadi industri berskala besar dan menyerap tenaga kerja di sekitar Desa Sukahurip.

2. Produsen diharapkan menjalankan kerjasama dengan pedagang perantara yang lebih banyak lagi, supaya dapat memasarkan sale pisang gulung lebih luas dan meningkatkan pendapatan yaitu dengan cara menggunakan internet (online), supermarket, dll.

\section{DAFTAR PUSTAKA}

Anita Eviana. 2017. Analisis Keragaan Agroindustri Keripik Pisang (Studi Kasus pada Agroindustri Panda Alami di Kecamatan Gendong Tataan Kabupaten Pesawaran). Skripsi. Universitas Lampung.

Assuari, S. 2002. Manajemen Pemasaran. PT Rajagrafindo Persada. Jakarta.

Assauri. S. 1999. Manajemen Operasi dan Produksi. Edisi Revisi. LPFE. Jakarta

Dedi,W., Eri,S., Eliza. 2016. Analisis usaha agroindustri kerupuk kulit sapi di kelurahan tuah karya Kecamatan Tampan Kota Pekan Baru. JOM FAPERTA UR VOL, 3 No. 2. Jurusan Agribisnis Fakultas Pertanian. Universitas Riau.

Endah, D., lucyana, T., Sonjanawati. 2018. Keragaan Usaha dan Nilai Tambah Pada Agroindustri keripik Tike (studi kasus di Desa Jumbbleng Kecamatan Losarang Indramayu). Jurnal Rekayasa Hijau.

Eyverson, R., Th. M. K., Priska A.P., Suwardi. Analisis Keuntungan Dan Nilai Tambah Agroindustri Manisan Pala Ud Putri Di Kota Bitung. ASE- Voleme 8 Nomor 1, Januari 2012: 31- 44.

Hasyim Al. 2012. Tataniaga Pertanian. Universitas Lampung. Bandar Lampung 
Kolter. P., Amstrong. G. 2008. PrinsipPrinsip Pemasaran. Erlangga. Jakarta.

Martodireso, E., Widada, AS. 2001, Terobosan Kemitraan Usaha dalam Era Globalisasi Kanisius, Yogyakarta.

Mubyarto.1993. Pengantar Ekonomi Pertanian. LP3ES. Jakarta.

Nurlina, R., T. Sarianti dan A. Karyadi. 2014. Studi Kelayakan Bisnis. Bogor. Institut Pertanian Bogor.

Prabawati,S., Sugayanti., Setyabudi,D,A. 2008. Teknologi Pasca Panen dan Teknik Pengolahan Buah Pisang. Penyuntingan Wisnu Broto. Balai Besar Penerbitan dan Pengembangan Pertanian.

Pratiwi, N,A., Hariyanto., Dariyanto, A. 2017. Peran Agroindustri Hulu dan Hilir Dalam Perekonomian dan Distribusi Pendapatan di Indonesia. Jurnal Manajemen dan Ageibisnis Vol 14 No.2 : 127-137.

Priyarsono, D,S., Bace, D. 2007. Industri Berbasis Pertanian : Arah Pengembangan Industri di Indonesia. Jurnal SOCA Vol 8 No. $3: 256-264$.

Rahayu. I. 2012. Analisis Keragaan Agroindustri Pengolahan Emping Melinjo di Kecamatan Cikadal Kabupaten Pandeglang. Skripsi. Fakultas Pertanian Universitas Lampung. Lampng.
Sheila, F.A, Dyah., A,L., Ismono, H. 2016. Keragaan Agroindustri Beras Siger (kasus di agroindustri toga sari Kabupaten Tulang Bawang dan Agroindustri Mekar Sari Kota Metro). JIIA, VOLUME 4 No. 3 Agustus 2016. Universitas Lampung.

Soekartawi. 1993. Agribisnis Teori dan Aplikasi. Rajawali Press. Jakarta.

Soekartawi. 2006. Analisis Usaha Tani. Jakarta: UI Press.

Suhartanto, M. Rahmat, Msi, Dr Ir, Sobir Msi, Heri Harti SP, Msi. 2012. Teknik Sehat Budidaya Pisang. Pusat Kajian Hortikultura Tropika. LPPM-IPB : Bogor.

Sumarni B, Siti Arwati. 2018. Keragaan Pemasaran Buah Naga (Hylocereus costaricensis) Dengan Pendekatan Structur, Conduct And Performance (SCP). Jurnal Galung Tropika, 7 (3) Desember 2018, hlm. 1844-197.

Suratiyah. 2006. Ilmu Usahatani. Penebar Swadaya. Jakarta.

Tiara, S.A., Dyah, A.H.L., Indriani, Y. 2017. Keragaan Agroindustri Tempe Anggota Primkopti Kabupaten Pesawaran. JIIA, VOLUME 5 No.3 Agustus 2017. Universitas Lampung.

Yuliani. 2004. Kemitraan Usaha Koperasi dan Strategi. Pustaka Sinar Harapan, Jakarta. 